\title{
A Randomized Trial of Laparoscopic versus Open Surgery for Rectal Cancer
}

\author{
H. Jaap Bonjer, M.D., Ph.D., Charlotte L. Deijen, M.D., Gabor A. Abis, M.D., \\ Miguel A. Cuesta, M.D., Ph.D., Martijn H.G.M. van der Pas, M.D., \\ Elly S.M. de Lange-de Klerk, M.D., Ph.D., Antonio M. Lacy, M.D., Ph.D., \\ Willem A. Bemelman, M.D., Ph.D., John Andersson, M.D., \\ Eva Angenete, M.D., Ph.D., Jacob Rosenberg, M.D., Ph.D., Alois Fuerst, M.D., Ph.D., \\ and Eva Haglind, M.D., Ph.D., for the COLOR II Study Group*
}

ABSTRACT

From VU University Medical Center (H.J.B., C.L.D., G.A.A., M.A.C., M.H.G.M.P., E.S.M.L.-K.) and Amsterdam Medical Center (W.A.B.) - both in Amsterdam; Hospital Clinic I Provincial de Barcelona, Barcelona (A.M.L.); the Department of Surgery, Institute of Clinical Sciences, Sahlgrenska Academy, University of Gothenburg, Sahlgrenska University Hospital-Östra, Gothenburg, Sweden (J.A., E.A., E.H.); Herlev Hospital, Department of Surgery, University of Copenhagen, Copenhagen (J.R.); and Caritas Krankenhaus St. Josef, Regensburg, Germany (A.F.). Address reprint requests to $\mathrm{Dr}$. Bonjer at VU University Medical Center, Department of Surgery, De Boelelaan 1117, 1081 HV Amsterdam, the Netherlands, or at j.bonjer@vumc.nl.

*A complete list of members of the Colorectal Cancer Laparoscopic or Open Resection (COLOR) II Study Group is provided in the Supplementary Appendix, available at NEJM.org.

N Engl J Med 2015;372:1324-32. DOI: 10.1056/NEJMoal414882

Copyright (C) 2015 Massachusetts Medical Society.

\section{BACKGROUND}

Laparoscopic resection of colorectal cancer is widely used. However, robust evidence to conclude that laparoscopic surgery and open surgery have similar outcomes in rectal cancer is lacking. A trial was designed to compare 3-year rates of cancer recurrence in the pelvic or perineal area (locoregional recurrence) and survival after laparoscopic and open resection of rectal cancer.

\section{METHODS}

In this international trial conducted in 30 hospitals, we randomly assigned patients with a solitary adenocarcinoma of the rectum within $15 \mathrm{~cm}$ of the anal verge, not invading adjacent tissues, and without distant metastases to undergo either laparoscopic or open surgery in a 2:1 ratio. The primary end point was locoregional recurrence 3 years after the index surgery. Secondary end points included disease-free and overall survival.

RESULTS

A total of 1044 patients were included (699 in the laparoscopic-surgery group and 345 in the open-surgery group). At 3 years, the locoregional recurrence rate was $5.0 \%$ in the two groups (difference, 0 percentage points; $90 \%$ confidence interval [CI], -2.6 to 2.6). Disease-free survival rates were $74.8 \%$ in the laparoscopic-surgery group and $70.8 \%$ in the open-surgery group (difference, 4.0 percentage points; $95 \%$ $\mathrm{CI},-1.9$ to 9.9$)$. Overall survival rates were $86.7 \%$ in the laparoscopic-surgery group and $83.6 \%$ in the open-surgery group (difference, 3.1 percentage points; 95\% CI, -1.6 to 7.8$)$.

\section{CONCLUSIONS}

Laparoscopic surgery in patients with rectal cancer was associated with rates of locoregional recurrence and disease-free and overall survival similar to those for open surgery. (Funded by Ethicon Endo-Surgery Europe and others; COLOR II ClinicalTrials.gov number, NCT00297791.) 
OLORECTAL CANCER IS THE THIRD MOST common cancer worldwide and accounts for nearly 1.4 million new cases and 694,000 deaths per year. Approximately one third of all colorectal cancers are localized in the rectum. ${ }^{1-4}$ Less than a half century ago, rectal cancer had a poor prognosis, with cancer recurrence rates in the pelvic or perineal area (locoregional recurrence) of up to $40 \%$ and 5-year survival rates after surgical resection of less than $50 \% .5,6$ In the $1980 \mathrm{~s}$, Heald and Ryall ${ }^{6}$ introduced a new surgical technique of complete removal of the fatty envelope surrounding the rectum (mesorectum), called total mesorectal excision. The adoption of total mesorectal excision combined with neoadjuvant chemoradiotherapy in selected patients has reduced locoregional recurrence rates to below $10 \%$ and improved cancer-free survival rates to more than $70 \% .^{7-10}$

Laparoscopic surgery has progressively replaced open colonic surgery in recent decades owing to favorable short-term outcomes, such as less pain, reduced blood loss, and improved recovery time. ${ }^{11}$ Initially, there was concern regarding the safety of laparoscopic colectomy after reports of cancer recurrence in the abdominal wall. ${ }^{12,13}$ In various trials in which patients with colon cancer were randomly assigned to undergo either open or laparoscopic surgery, evidence was obtained that laparoscopic surgery was associated with similar disease-free and overall survival rates as open surgery. ${ }^{14,15}$ However, evidence is lacking from large, randomized clinical trials indicating that survival after laparoscopic resection of rectal cancer is not inferior to open surgery. We previously reported that laparoscopic surgery in patients with rectal cancer was associated with similar surgical safety and improved recovery time, as compared with open surgery. ${ }^{16}$ In the Colorectal Cancer Laparoscopic or Open Resection (COLOR) II trial, we report the long-term rates of locoregional recurrence and survival in patients who were randomly assigned to undergo one of the two procedures.

\section{METHODS}

\section{STUDY DESIGN AND OVERSIGHT}

The COLOR II trial was a noninferiority, openlabel, multicenter trial conducted at 30 centers in 8 countries. The study was designed by members of the protocol committee. The local investigators and the trial manager gathered the data. The authors analyzed the data and vouch for the accuracy of the data and the analyses and the fidelity of the study to the protocol (available with the full text of this article at NEJM.org). The authors wrote the manuscript and made the decision to submit the manuscript for publication. The sponsor of the study, Ethicon Endo-Surgery Europe (a subsidiary of Johnson \& Johnson), had no role in the study design, data gathering, analyses and interpretation, or writing of the manuscript.

\section{PATIENTS}

Patients with a solitary adenocarcinoma of the rectum within $15 \mathrm{~cm}$ from the anal verge without distant metastases who were candidates for elective surgery were eligible for inclusion. The localization of the tumor was categorized as the upper rectum (distal border of tumor, 10 to $15 \mathrm{~cm}$ from the anal verge), middle rectum ( 5 to $10 \mathrm{~cm}$ from the anal verge), or lower rectum $(<5 \mathrm{~cm}$ from the anal verge). Patients with T4 tumors or T3 tumors within $2 \mathrm{~mm}$ of the endopelvic fascia, as determined on computed tomography (CT) or magnetic resonance imaging (MRI), were excluded. Other exclusion criteria have been reported previously. ${ }^{16}$ The study was approved by the institutional review board at each participating center. All patients provided written informed consent.

\section{RANDOMIZATION}

Randomization was performed at the patient level. Laparoscopic and open surgery were performed at all participating centers. Eligible patients were randomly assigned in a 2:1 ratio to undergo either laparoscopy or open surgery according to a list of randomization numbers with treatment assignments. This list was computergenerated, with stratification according to hospital, tumor location, and the presence or absence of preoperative radiotherapy. An Internet application allowed central randomization.

\section{PROCEDURES AND QUALITY CONTROL}

The use of neoadjuvant therapy was determined by multidisciplinary cancer boards at each participating hospital, according to local standards, without differences between the laparoscopicsurgery group and the open-surgery group. All procedures were required to comply with the principles of total mesorectal excision or partial mesorectal excision if the cancer was located in the upper part of the rectum. ${ }^{6}$

The selection of centers for participation in 
the trial was based on stringent quality assessment by the study management committee to confirm the use of proper surgical technique. Unedited recordings of five consecutive laparoscopic total mesorectal excisions were evaluated. The respective pathology reports of these five consecutive cases were reviewed to confirm completeness of the specimens. Pathologists adhered to standardized processing and assessment of specimens, as described in detail in the trial protocol, to ensure accurate reporting by all participating centers. ${ }^{16}$ The circumferential resection margin was defined as "involved" when tumor cells were present within $2 \mathrm{~mm}$ from the lateral surface of the mesorectum.

\section{END POINTS}

The primary end point was locoregional recurrence 3 years after the index surgery. Secondary end points included disease-free and overall survival.

\section{FOLLOW-UP}

Minimal required follow-up included annual clinical examinations for 5 years after surgery. Three years after the index surgery, CT or MRI of the pelvis combined with imaging of the liver and the chest were performed. Recurrent disease was defined as the presence of locoregional recurrence, the presence of distant metastases, or death from rectal cancer.

\section{STATISTICAL ANALYSIS}

We used the Kaplan-Meier method to estimate the difference in recurrence rates between the two study groups at 3 years postoperatively. Laparoscopic surgery was considered to be noninferior to open surgery if the one-sided $95 \%$ confidence interval for the difference in locoregional recurrence rates excluded an absolute difference of 5 percentage points or more. With 1000 patients who could be evaluated at a ratio of $2: 1$, the power of the noninferiority test was $80 \%$ at a locoregional recurrence rate of $10 \%$ in the open-surgery group.

All analyses were performed on an intentionto-treat basis. We used the Kaplan-Meier method to compare rates of recurrence, disease-free survival, and overall survival at 3 years. The onesided $95 \%$ confidence interval for the betweengroup difference in locoregional recurrence corresponds to the upper limit of the two-sided $90 \%$ confidence interval for this difference. For survival rates, two-sided $95 \%$ confidence inter- vals were calculated. In addition, we performed as-treated analyses for locoregional recurrence, disease-free survival, and overall survival.

\section{RESULTS}

\section{PATIENTS}

From January 2004 through May 2010, a total of 1103 patients with rectal cancer underwent randomization. Of these patients, 739 were assigned to undergo laparoscopic surgery and 364 to undergo open surgery. After the exclusion of $59 \mathrm{pa}-$ tients following randomization, 1044 patients (699 in the laparoscopic-surgery group and 345 patients in the open-surgery group) were included in the analysis (Fig. 1). In total, 1036 patients were included in the long-term analyses.

At the 3-year follow-up, data were available for 771 patients $(74 \%)$ regarding locoregional recurrence, 923 (89\%) regarding disease-free survival, and 903 (87\%) regarding overall survival. The clinical characteristics of the patients were similar in the two groups, as were the proportions of patients who received neoadjuvant chemoradiotherapy (Table 1).

\section{SHORT-TERM OUTCOMES}

Five patients who were randomly assigned to the open-surgery group underwent laparoscopic surgery. Of these patients, three requested laparoscopic surgery after randomization, and the reason for crossover was unknown for the other two patients. In addition, seven patients in the laparoscopic-surgery group underwent open surgery: one owing to poor pulmonary condition, five because no laparoscopic surgeon was available, and one for an unknown reason. A total of $86 \%$ of laparoscopic and open procedures were performed by surgeons who had performed both laparoscopic and open surgeries for rectal cancer. The conversion rate from laparoscopic surgery to open surgery was $16 \%$. In the laparoscopic-surgery group, the operating time was 52 minutes longer, bowel function returned 1 day earlier, and the hospital stay was 1 day shorter than in the opensurgery group. There were no significant differences in the rates of anastomotic leaking, complication, or death. ${ }^{16}$

\section{PATHOLOGICAL ANALYSES}

There were no significant between-group differences for all lesions with respect to macroscopic 


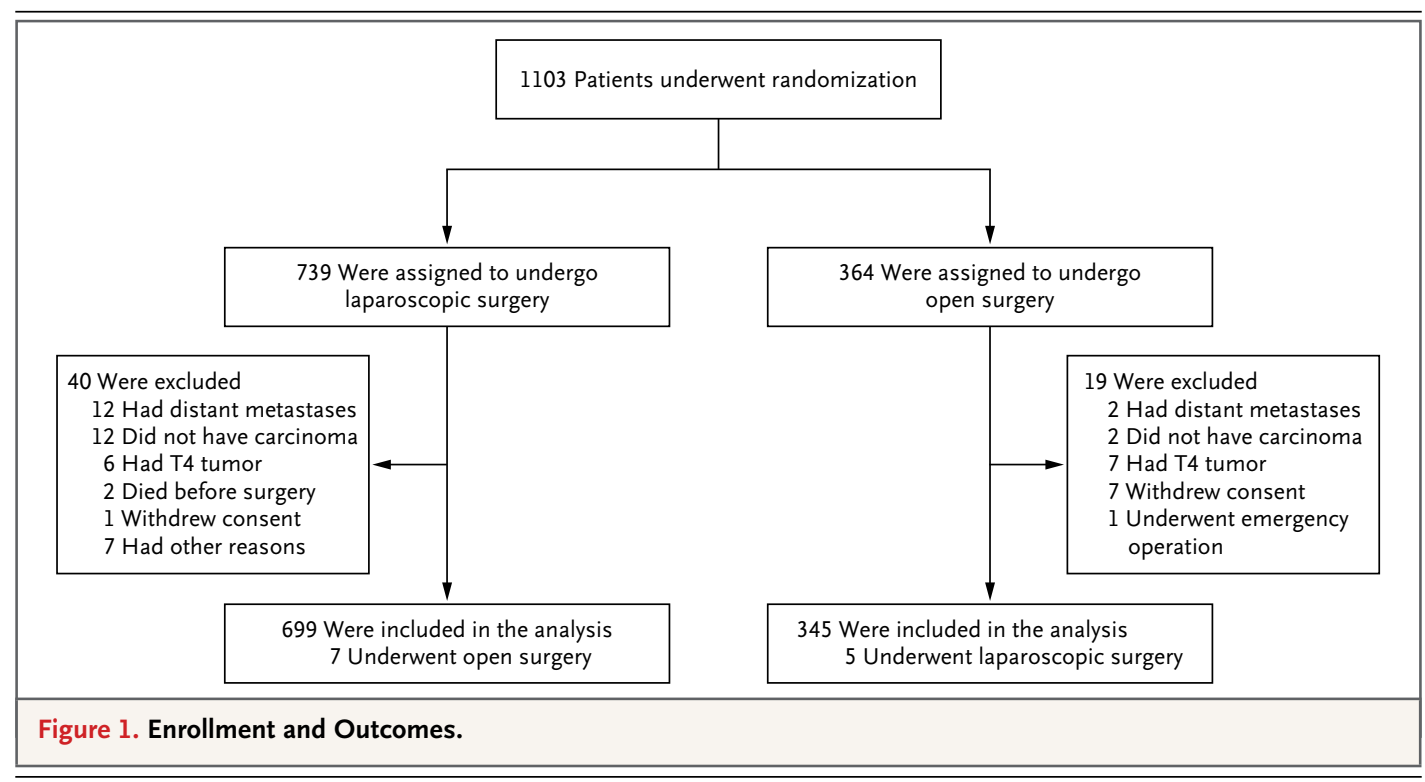

completeness of the mesorectum, involved circumferential resection margins (Tables 1 and 2), or distal resection margins (median, $3.0 \mathrm{~cm}$ in the two groups).

\section{LOCOREGIONAL RECURRENCE}

At 3 years, the rate of locoregional recurrence was $5.0 \%$ in each of the study groups (31 patients in the laparoscopic-surgery group and 15 in the open-surgery group) (Table 2). The upper limit of the $90 \%$ confidence interval for the absolute between-group difference in the rate of locoregional recurrence ( 2.6 percentage points) was below the noninferiority margin of 5 percentage points. In the intention-to-treat analysis, rates of locoregional recurrence of upper rectal cancers were $3.5 \%$ in the laparoscopic-surgery group and $2.9 \%$ in the open-surgery group (difference, 0.6 percentage points; $90 \% \mathrm{CI},-2.9$ to 4.1 ). In patients with middle rectal cancers, locoregional recurrence rates were $6.5 \%$ and $2.4 \%$, respectively (difference, 4.1 percentage points; $90 \%$ CI, 0.7 to 7.5 ); in patients with lower rectal cancers, the rates were $4.4 \%$ and $11.7 \%$, respectively (difference, -7.3 percentage points; $90 \% \mathrm{CI},-13.9$ to -0.7 ).

In the as-treated analysis, the locoregional recurrence rates in patients with upper rectal cancers were $3.0 \%$ in the laparoscopic-surgery group and 3.9\% in the open-surgery group (difference, -0.9 percentage points; $90 \% \mathrm{CI},-4.6$ to 2.8). In patients with middle rectal cancers, locoregional recurrence rates were $5.7 \%$ and $4.1 \%$, respectively (difference, 1.6 percentage points; $90 \%$ CI, -2.3 to 5.5); in patients with lower rectal cancers, the rates were $3.8 \%$ and $12.7 \%$, respectively (difference -8.9 percentage points; $90 \%$ CI, -15.6 to -2.2 ). Among 46 patients with locoregional recurrence at 3 years, 27 patients had distant metastases as well.

\section{DISEASE-FREE AND OVERALL SURVIVAL}

At 3 years, the rate of disease-free survival was $74.8 \%$ in the laparoscopic-surgery group and $70.8 \%$ in the open-surgery group (difference, 4.0 percentage points; 95\% CI, -1.9 to 9.9) (Fig. 2). In patients with stage I or II rectal cancer, rates of disease-free survival were similar in the two groups, whereas in patients with stage III disease, the rate of disease-free survival was $64.9 \%$ in the laparoscopic-surgery group and $52.0 \%$ in the open-surgery group (difference, 12.9 percentage points; $95 \%$ CI, 2.2 to 23.6).

At 3 years after surgery, 145 patients had died, accounting for an overall survival rate of $86.7 \%$ in the laparoscopic-surgery group and $83.6 \%$ in the open-surgery group (difference, 3.1 percentage points; 95\% CI, -1.6 to 7.8) (Fig. 3). Overall survival rates according to disease stage were also similar in the two groups.

Distant metastases at 3 years after surgery were reported in $19.1 \%$ of the patients in the laparoscopic-surgery group and $22.1 \%$ of those in the open-surgery group, including one portsite metastasis in the laparoscopic-surgery group 
Table 1. Clinical and Pathological Characteristics of the Patients at Baseline.*

\begin{tabular}{|c|c|c|}
\hline Characteristic & $\begin{array}{l}\text { Laparoscopic Surgery } \\
\qquad(\mathrm{N}=699)\end{array}$ & $\begin{array}{l}\text { Open Surgery } \\
(\mathrm{N}=\mathbf{3 4 5})\end{array}$ \\
\hline \multicolumn{3}{|l|}{ Sex-no. (\%) } \\
\hline Male & $448(64)$ & $211(61)$ \\
\hline Female & $251(36)$ & $134(39)$ \\
\hline Age $-y r$ & $66.8 \pm 10.5$ & $65.8 \pm 10.9$ \\
\hline \multicolumn{3}{|l|}{$\begin{array}{c}\text { American Society of Anesthesiologists } \\
\text { classification — no. (\%) }\end{array}$} \\
\hline I: healthy & $156(22)$ & $65(19)$ \\
\hline II: mild systemic disease & $386(55)$ & $211(61)$ \\
\hline III: severe systemic disease & $131(19)$ & $61(18)$ \\
\hline $\begin{array}{l}\text { IV: severe life-threatening systemic } \\
\text { disease }\end{array}$ & $5(1)$ & $1(<1)$ \\
\hline Missing data & $21(3)$ & $7(2)$ \\
\hline Body-mass index' & $26.1 \pm 4.5$ & $26.5 \pm 4.7$ \\
\hline \multicolumn{3}{|l|}{$\begin{array}{l}\text { Distance of tumor from anal verge - } \\
\text { no. (\%) }\end{array}$} \\
\hline Upper rectum: 10 to $15 \mathrm{~cm}$ & $223(32)$ & $116(34)$ \\
\hline Middle rectum: 5 to $<10 \mathrm{~cm}$ & $273(39)$ & $136(39)$ \\
\hline Lower rectum: $<5 \mathrm{~cm}$ & $203(29)$ & $93(27)$ \\
\hline \multicolumn{3}{|l|}{ Clinical stage - no. (\%) } \\
\hline 1 & $201(29)$ & $96(28)$ \\
\hline II & $209(30)$ & $107(31)$ \\
\hline III & $257(37)$ & $126(37)$ \\
\hline Missing data & $32(5)$ & $16(5)$ \\
\hline Preoperative radiotherapy — no. (\%) & $412(59)$ & $199(58)$ \\
\hline $\begin{array}{l}\text { Preoperative chemotherapy — no./ } \\
\text { total no. (\%) }\end{array}$ & $196 / 609(32)$ & $99 / 295(34)$ \\
\hline $\begin{array}{l}\text { No residual tumor — no./total no. } \\
\qquad(\%) \ddagger\end{array}$ & $33 / 412(8)$ & $19 / 199(10)$ \\
\hline \multicolumn{3}{|l|}{ Pathological stage - no. (\%)』 } \\
\hline 1 & $231(33)$ & $107(31)$ \\
\hline II & $180(26)$ & $91(26)$ \\
\hline III & $233(33)$ & $125(36)$ \\
\hline IV & $4(1)$ & 0 \\
\hline Missing data & $18(3)$ & $3(1)$ \\
\hline \multicolumn{3}{|l|}{$\begin{array}{l}\text { Macroscopic completeness of resec- } \\
\text { tion - no. (\%) }\end{array}$} \\
\hline Complete & $589(84)$ & $303(88)$ \\
\hline Partially complete & $58(8)$ & $19(6)$ \\
\hline Incomplete & $19(3)$ & $9(3)$ \\
\hline Missing data & $33(5)$ & $14(4)$ \\
\hline \multicolumn{3}{|l|}{ Lymph nodes harvested } \\
\hline Median no. (IQR) & $13(10-18)$ & $14(10-19)$ \\
\hline Missing data - no. (\%) & $16(2)$ & $4(1)$ \\
\hline
\end{tabular}

* Plus-minus values are means \pm SD. There were no significant differences between the groups. Percentages may not total 100 because of rounding. IQR denotes interquartile range.

$\uparrow$ The body-mass index is the weight in kilograms divided by the square of the height in meters.

$¥$ The denominator is the number of patients who received preoperative radiotherapy.

$\int$ The patients with no residual tumor were not included in the analysis of pathological stage. and one tumor recurrence in the laparotomy wound in the open-surgery group.

\section{DISCUSSION}

In this trial, we compared the rates of locoregional recurrence of rectal cancer after laparoscopic or open resection. Locoregional recurrences were recorded in $5.0 \%$ of the patients in each of the two groups. In the Dutch trial of total mesorectal excision by Kapiteijn et al., ${ }^{8}$ among 1805 patients with rectal cancer who underwent open resection, the locoregional recurrence rate at 2 years was $5.3 \%$, a rate similar to that in our study.

In the Conventional versus LaparoscopicAssisted Surgery in Colorectal Cancer (CLASICC) trial, the first multicenter, randomized study to determine the effect of laparoscopic surgery on rectal-cancer outcomes involving 381 patients, the locoregional recurrence rate at 3 years was 9.7\% after laparoscopic surgery and $10.1 \%$ after open surgery. ${ }^{17}$ The presence of involved circumferential resection margins, which predispose patients to locoregional recurrence, were observed in $16 \%$ of the patients after laparoscopic surgery in the CLASICC trial, as compared with $10 \%$ of those in the laparoscopicsurgery group in our study. ${ }^{18,19}$ Recently, in the Comparison of Open versus Laparoscopic Surgery for Mid or Low Rectal Cancer after Neoadjuvant Chemoradiotherapy (COREAN) study ${ }^{10}$ involving 340 patients with cancer of the middle or lower rectum who had received preoperative chemoradiotherapy, rates of locoregional recurrence were $2.6 \%$ after laparoscopic surgery and $4.9 \%$ after open surgery. The presence of involved circumferential resection margins in the COREAN trial $(2.9 \%$ after laparoscopic surgery and $4.1 \%$ after open surgery) were lower than those in our study. ${ }^{20}$ However, we considered circumferential resection margins as being involved when tumor cells were present within $2 \mathrm{~mm}$ from the lateral surface of the mesorectum, whereas the COREAN study group used a $1-\mathrm{mm}$ margin. The use of a $2-\mathrm{mm}$ margin yields a higher rate of involved circumferential resection margins. ${ }^{16}$

In our study, laparoscopic surgery in patients with cancer in the lower third of the rectum was associated with a lower rate of involved circumferential resection margin and a lower locoregional recurrence rate than was open surgery. During laparoscopic surgery, narrow spaces such 


\begin{tabular}{|c|c|c|c|c|c|c|}
\hline \multirow[t]{3}{*}{ Type of Lesion and Surgery } & \multicolumn{2}{|c|}{$\begin{array}{c}\text { Involved Circumferential Resection } \\
\text { Margin* }\end{array}$} & \multicolumn{2}{|c|}{$\begin{array}{l}\text { Locoregional Recurrence in } \\
\text { Intention-to-Treat Population }\end{array}$} & \multicolumn{2}{|c|}{$\begin{array}{l}\text { Locoregional Recurrence } \\
\text { in As-Treated Population }\end{array}$} \\
\hline & $\begin{array}{l}\text { Patients with } \\
\text { Finding } \dagger^{-}\end{array}$ & $\begin{array}{l}\text { Between-Group } \\
\text { Differencet: }\end{array}$ & Rate & $\begin{array}{l}\text { Between-Group } \\
\text { Differencet: }\end{array}$ & Rate & $\begin{array}{l}\text { Between-Group } \\
\text { Differencet: }\end{array}$ \\
\hline & no./total no. (\%) & $\begin{array}{l}\text { percentage points } \\
(95 \% \mathrm{Cl})\end{array}$ & $\%$ & $\begin{array}{l}\text { percentage points } \\
(90 \% \mathrm{Cl})\end{array}$ & $\%$ & $\begin{array}{l}\text { percentage points } \\
(90 \% \mathrm{Cl})\end{array}$ \\
\hline \multicolumn{7}{|l|}{ All lesions } \\
\hline Laparoscopic surgery & $56 / 588(10)$ & $-0.5(-4.9$ to 3.5$)$ & 5.0 & 0.0 (-2.6 to 2.6$)$ & 4.3 & $-2.0(-4.7$ to 0.7$)$ \\
\hline Open surgery & $30 / 300(10)$ & & 5.0 & & 6.3 & \\
\hline \multicolumn{7}{|l|}{ Upper rectal lesion } \\
\hline Laparoscopic surgery & $18 / 196(9)$ & $-0.1(-8.2$ to 6.4$)$ & 3.5 & 0.6 (-2.9 to 4.1$)$ & 3.0 & $-0.9(-4.6$ to 2.8$)$ \\
\hline Open surgery & $9 / 97(9)$ & & 2.9 & & 3.9 & \\
\hline \multicolumn{7}{|l|}{ Middle rectal lesion } \\
\hline Laparoscopic surgery & $22 / 228(10)$ & $6.2(0.1$ to 11.2$)$ & 6.5 & 4.1 (0.7 to 7.5$)$ & 5.7 & $1.6(-2.3$ to 5.5$)$ \\
\hline Open surgery & 4/115 (3) & & 2.4 & & 4.1 & \\
\hline \multicolumn{7}{|l|}{ Lower rectal lesion } \\
\hline Laparoscopic surgery & $15 / 164(9)$ & $-12.4(-23.2$ to -3.0$)$ & 4.4 & $-7.3(-13.9$ to -0.7$)$ & 3.8 & $-8.9(-15.6$ to -2.2$)$ \\
\hline Open surgery & $17 / 79(22)$ & & 11.7 & & 12.7 & \\
\hline
\end{tabular}

* An involved circumferential resection margin was defined as the presence of tumor cells within $2 \mathrm{~mm}$ of the lateral surface of the mesorectum. This finding is a risk factor for locoregional recurrence (i.e., recurrence in the pelvic or perineal area).

$\uparrow$ The denominator for the percentage calculation in this category was the number of patients without complete remission.

Hetween-group differences were calculated by subtracting the percentage of patients with the finding in the open-surgery group from the percentage in the laparoscopic-surgery group.

as the lower pelvis are better visualized than in open surgery owing to the use of a laparoscope, which projects a magnified and well-illuminated image of the operative field on the monitors. A clear view is of paramount importance to accomplish a resection of the cancer with sufficient margins. As a result of tapering of the mesorectum at the level of the pelvic floor, tissue margins around low rectal cancers are smaller than those around tumors located in the middle or upper rectum, which predisposes such tumors to incomplete radical resection. ${ }^{21}$ Therefore, a procedure called extralevatory abdominoperineal rectum extirpation (ELAPE), in which a part of the pelvic floor musculature is resected through a perineal approach, has been introduced. During the past decade, the ELAPE principle was introduced but was not included in the COLOR II study protocol. ${ }^{22}$ However, the debate on the value of this technique continues.

The disease-free survival rates at 3 years in our study were $74.8 \%$ after laparoscopic surgery and $70.8 \%$ after open surgery, as compared with rates of $79.2 \%$ and $72.5 \%$, respectively, during the same follow-up period in the COREAN study. ${ }^{10}$ In our study, among patients with stage III disease, disease-free survival rates were $64.9 \%$ after laparoscopic surgery and 52.0\% after open surgery. A similar finding was reported by Lacy and colleagues ${ }^{15}$ among patients who underwent laparoscopic resection of lymph-node-positive colon cancers. These observations may confirm the experimental findings that less surgical trauma associated with the use of laparoscopic techniques reduces tumor recurrence. ${ }^{23}$ In a study involving patients undergoing laparoscopic and open colonic resection, laparoscopic surgery was followed by attenuated stress responses and improved preservation of immune function. ${ }^{24}$ Further studies are necessary to determine whether laparoscopic surgery for cancer is associated with improved survival.

The size of the cohort in our study allowed for the use of a noninferiority margin of 5 percentage points, whereas in the smaller COREAN trial, the noninferiority margin was 15 percentage points. ${ }^{20}$ Since centers in eight countries in Europe, North America, and Asia participated in our study, the outcomes appear to be applicable to surgical practice in general.

Rectal-cancer surgery, regardless of which technique is used, is technically demanding and requires sufficient training to be performed safely. We verified the surgical quality of laparo- 


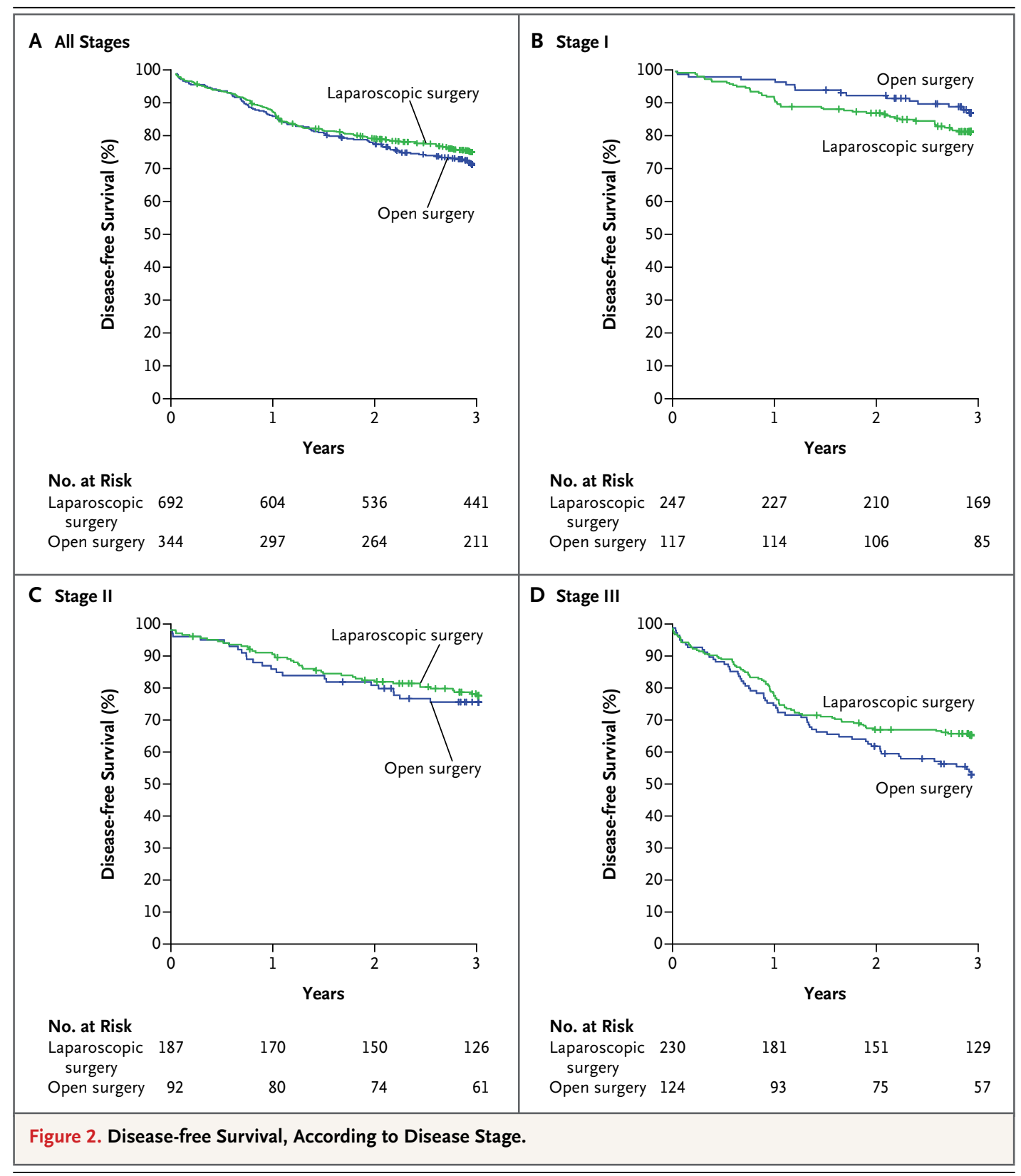

scopic total mesorectal excision by reviewing unedited recordings of five consecutive laparoscopic procedures for each center. Laparoscopic surgical expertise is difficult to measure objectively but is reflected to a certain extent by operative time and conversion rate. ${ }^{25}$ The median operating times for laparoscopic procedures were 240 minutes in our study and 245 minutes in the COREAN trial; the latter obviously was recorded by highly skilled surgeons, given the low conversion rate of only $1 \%$ in that study. ${ }^{20}$
The conversion rate in our study remained 16\% throughout the study period, whereas a decline in the conversion rate from $38 \%$ in the first year to $16 \%$ in the last year of the trial was reported by the CLASICC group. ${ }^{19}$

In our study, patients with T4 and T3 lesions within $2 \mathrm{~mm}$ of the endopelvic fascia were excluded because laparoscopic resection of these large tumors is very difficult and could result in less-than-complete resection with subsequent higher rates of locoregional recurrence. There- 


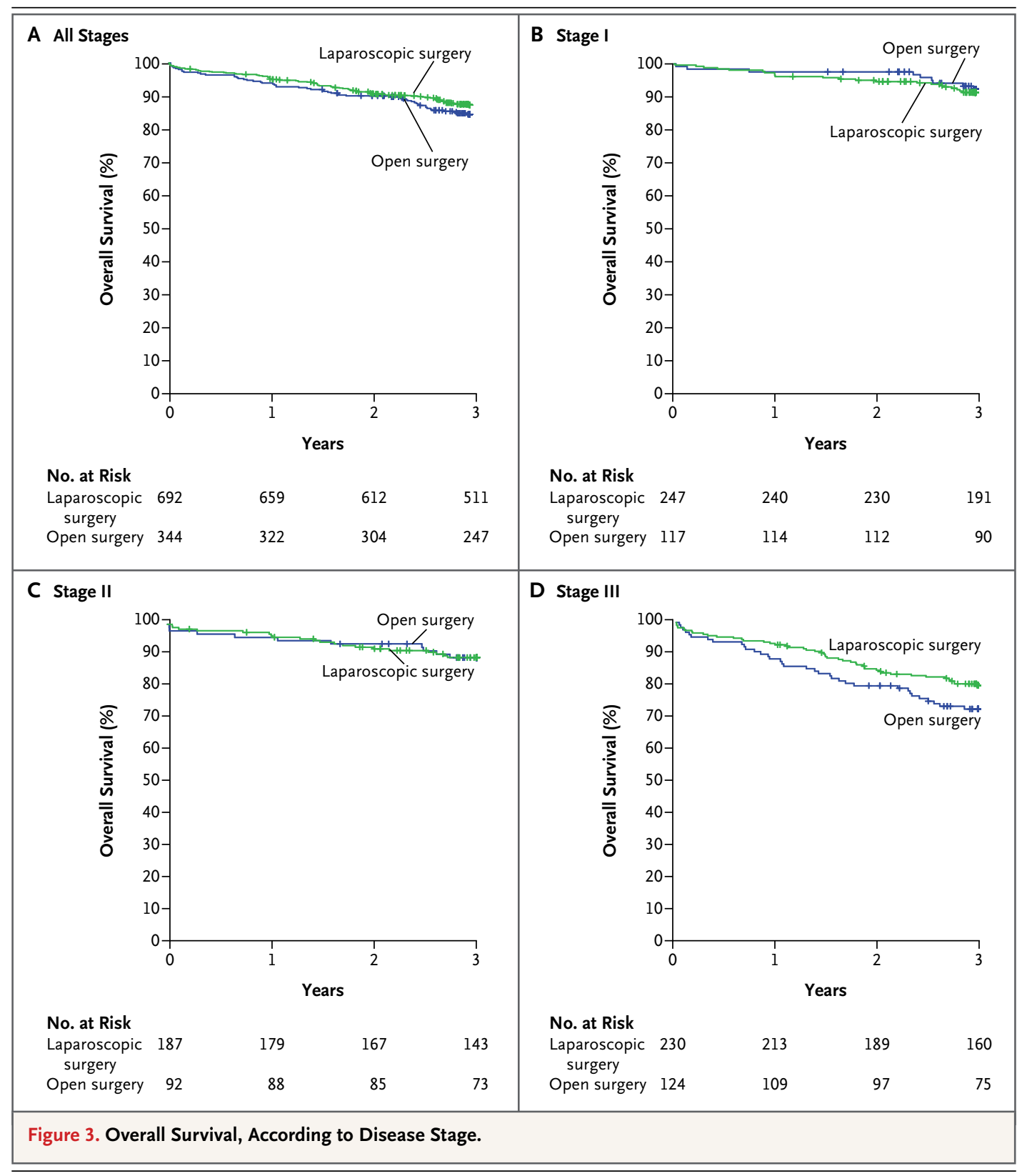

fore, we do not recommend laparoscopic surgery in patients with $\mathrm{T} 4$ or $\mathrm{T} 3$ rectal cancers with threatened circumferential margins.

A limitation of our study is the absence of centralized macroscopic and microscopic evaluation of the resected specimens. However, all pathologists adhered to a detailed standardized protocol. Another limitation is the use of different imaging methods to determine the location of the tumor. It would have been preferable to standardize the imaging technique of the pelvis and calibrate the measurements centrally by independent professionals.

Some surgeons insert one of their hands through a gastight port in the abdomen during laparoscopic colorectal surgery to allow for manual retraction of tissues and tactile feedback, a procedure called hand-assisted laparoscopic surgery. ${ }^{26}$ The group who designed the study thought that a hand would obstruct the laparoscopic view of the narrow pelvis, so this technique was not part of the current protocol. 
In conclusion, long-term outcomes of the COLOR II trial indicate that laparoscopic surgery is as safe and effective as open surgery in patients with rectal cancers without invasion of adjacent tissues.

Supported by Ethicon Endo-Surgery Europe; grants from the Swedish Cancer Society (2010/593 and 2013/497); the Health and Medical Care Committee of the Regional Executive Board, Region Västra Götaland, and an agreement concerning re- search and education of doctors, Sahlgrenska University Hospital, Gothenburg, Sweden; the Departments of Surgery and Biostatistics, Erasmus University Medical Center, Rotterdam, the Netherlands; the Department of Surgery, Dalhousie University, Halifax, NS, Canada; and the Department of Surgery, VU University Medical Center, Amsterdam.

Disclosure forms provided by the authors are available with the full text of this article at NEJM.org.

We thank Karen Inglis and Kevin Druhan of Dalhousie University for coordinating the trial and gathering and processing data.
REFERENCES

1. Ferlay J, Soerjomataram I, Ervik M, et al. GLOBOCAN 2012: estimated cancer incidence, mortality, and prevalence worldwide in 2012. Lyon, France: International Agency for Research on Cancer, 2013 (http://globocan.iarc.fr).

2. Cancer facts and figures 2014. Atlanta: American Cancer Society, 2014 (http://www .cancer.org/acs/groups/content/@research/ documents/webcontent/acspc-042151.pdf). 3. National Bowel Cancer Audit annual report 2013. London: Health and Social Care Information Centre, 2013 (http:/l www.hqip.org.uk/assets/NCAPOP-Library/ NCAPOP-2013-14/Bowel-Cancer-Audit-Jul -2013-MAINREPORT.pdf).

4. Van Leersum NJ, Snijders HS, Henneman D, et al. The Dutch Surgical Colorectal Audit. Eur J Oncol 2013;39:1063-70.

5. Slaney G. Results of treatment of carcinoma of the colon and rectum. Mod Trends Surg 1971;3:69-89.

6. Heald RJ, Ryall RD. Recurrence and survival after total mesorectal excision for rectal cancer. Lancet 1986;1:1479-82.

7. MacFarlane JK, Ryall RD, Heald RJ. Mesorectal excision for rectal cancer. Lancet 1993;341:457-60.

8. Kapiteijn E, Marijnen CA, Nagtegaal ID, et al. Preoperative radiotherapy combined with total mesorectal excision for resectable rectal cancer. $\mathrm{N}$ Engl J Med 2001;345:638-46

9. Laurent $C$, Leblanc $F$, Wütrich $P$, Scheffler M, Rullier E. Laparoscopic versus open surgery for rectal cancer: longterm oncologic results. Ann Surg 2009; 250:54-61.

10. Jeong SY, Park JW, Nam BH, et al. Open versus laparoscopic surgery for midrectal or low-rectal cancer after neoadjuvant chemoradiotherapy (COREAN trial): survival outcomes of an open-label, noninferiority, randomised controlled trial. Lancet Oncol 2014;15:767-74.
11. Veldkamp R, Kuhry E, Hop WC, et al. Laparoscopic surgery versus open surgery for colon cancer: short-term outcomes of a randomised trial. Lancet Oncol 2005;6: 477-84.

12. Berends FJ, Kazemier G, Bonjer HJ, Lange JF. Subcutaneous metastases after laparoscopic colectomy. Lancet 1994;344: 58.

13. Cirocco WC, Schwartzman A, Golub RW. Abdominal wall recurrence after laparoscopic colectomy for colon cancer. Surgery 1994;116:842-6.

14. Colon Cancer Laparoscopic or Open Resection Study Group. Survival after laparoscopic surgery versus open surgery for colon cancer: long-term outcome of a randomised clinical trial. Lancet Oncol 2009;10:44-52.

15. Lacy AM, García-Valdecasas JC, Delgado $\mathrm{S}$, et al. Laparoscopy-assisted colectomy versus open colectomy for treatment of non-metastatic colon cancer: a randomised trial. Lancet 2002;359:2224-9.

16. van der Pas $\mathrm{MH}$, Haglind E, Cuesta MA, et al. Laparoscopic versus open surgery for rectal cancer (COLOR II): shortterm outcomes of a randomised, phase 3 trial. Lancet Oncol 2013;14:210-8.

17. Jayne DG, Guillou PJ, Thorpe $H$, et al. Randomized trial of laparoscopic-assisted resection of colorectal carcinoma: 3-year results of the UK MRC CLASICC Trial Group. J Clin Oncol 2007;25:3061-8.

18. Nagtegaal ID, Marijnen CA, Kranenbarg EK, van de Velde CJ, van Krieken JH. Circumferential margin involvement is still an important predictor of local recurrence in rectal carcinoma: not one millimeter but two millimeters is the limit. Am J Surg Pathol 2002;26:350-7.

19. Guillou PJ, Quirke P, Thorpe H, et al. Short-term endpoints of conventional versus laparoscopic-assisted surgery in patients with colorectal cancer (MRC
CLASICC trial): multicentre, randomised controlled trial. Lancet 2005;365:1718-26. 20. Kang SB, Park JW, Jeong SY, et al. Open versus laparoscopic surgery for mid or low rectal cancer after neoadjuvant chemoradiotherapy (COREAN trial): shortterm outcomes of an open-label randomised controlled trial. Lancet Oncol 2010;11:637-45.

21. Marr R, Birbeck K, Garvican J, et al. The modern abdominoperineal excision: the next challenge after total mesorectal excision. Ann Surg 2005;242:74-82.

22. Holm T, Ljung A, Häggmark T, Jurell G, Lagergren J. Extended abdominoperineal resection with gluteus maximus flap reconstruction of the pelvic floor for rectal cancer. Br J Surg 2007;94:232-8.

23. Bouvy ND, Marquet RL, Jeekel J, Bonjer HJ. Laparoscopic surgery is associated with less tumour growth stimulation than conventional surgery: an experimental study. Br J Surg 1997;84:358-61.

24. Veenhof AA, Vlug MS, van der Pas $\mathrm{MH}$, et al. Surgical stress response and postoperative immune function after laparoscopy or open surgery with fast track or standard perioperative care: a randomized trial. Ann Surg 2012;255:216-21.

25. Harrysson IJ, Cook J, Sirimanna P, Feldman LS, Darzi A, Aggarwal R. Systematic review of learning curves for minimally invasive abdominal surgery: a review of the methodology of data collection, depiction of outcomes, and statistical analysis. Ann Surg 2014;260:37-45.

26. Milsom JW, de Oliveira O Jr, Trencheva KI, Pandey S, Lee SW, Sonoda T. Longterm outcomes of patients undergoing curative laparoscopic surgery for mid and low rectal cancer. Dis Colon Rectum 2009; 52:1215-22.

Copyright (C) 2015 Massachusetts Medical Society.

NEJM CLINICAL PRACTICE CENTER

Explore a new page designed specifically for practicing clinicians, the NEJM Clinical Practice Center, at NEJM.org/clinical-practice-center. Find practice-changing research, reviews from our Clinical Practice series, a curated collection of clinical cases, and interactive features designed to hone your diagnostic skills. 